\title{
Invasive species' leaf traits and dissimilarity from natives shape their impact on nitrogen cycling: a meta-analysis
}

\author{
Marissa R. Lee ${ }^{1}$, Emily S. Bernhardt ${ }^{1}$, Peter M. van Bodegom², J. Hans C. Cornelissen ${ }^{3}$, Jens Kattge ${ }^{4,5}$, \\ Daniel C. Laughlin ${ }^{6}$, Ülo Niinemets ${ }^{7}$, Josep Peñuelas ${ }^{8,9}$, Peter B. Reich ${ }^{10,11}$, Benjamin Yguel ${ }^{12,13}$ and \\ Justin P. Wright ${ }^{1}$
}

${ }^{1}$ Department of Biology, Duke University, 130 Science Drive, Durham, NC 27708, USA; ${ }^{2}$ Institute of Environmental Sciences, Leiden University, Einsteinweg 2, Leiden 2333 CC, the

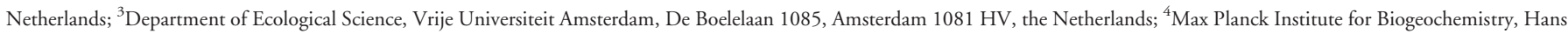

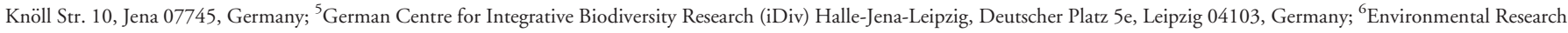

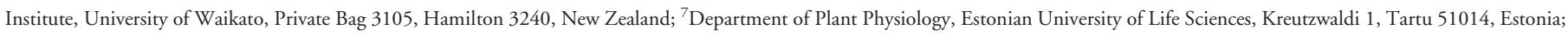
${ }^{8}$ CSIC, Global Ecology Unit, CREAF-CSIC-UAB, Cerdanyola del Vallès, Barcelona, Catalonia 08193, Spain; ${ }^{9}$ CREAF, Cerdanyola del Vallès, Barcelona, Catalonia 08193, Spain;

${ }^{10}$ Department of Forest Resources, University of Minnesota, St Paul, MN 55108, USA; ${ }^{11}$ Hawkesbury Institute for the Environment, Western Sydney University, Penrith, NSW 2751,

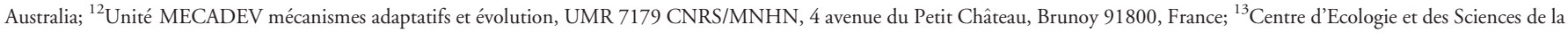
Conservation (CESCO-UMR 7204), Sorbonne Universités-MNHN-CNRS-UPMC, CP51, 55-61 rue Buffon, Paris 75005, France

Author for correspondence:
Marissa R. Lee
Tel: +1919357 3385
Email: mrl17@duke.edu

Received: 16 May 2016

Accepted: 21 June 2016

New Phytologist (2017) 213: 128-139

doi: $10.1111 /$ nph. 14115

Key words: functional trait, leaf carbon to nitrogen, leaf nitrogen content, mineralization, nitrogen cycling, nutrient-use strategy, plant invasions.

\section{Summary}

- Many exotic species have little apparent impact on ecosystem processes, whereas others have dramatic consequences for human and ecosystem health. There is growing evidence that invasions foster eutrophication. We need to identify species that are harmful and systems that are vulnerable to anticipate these consequences. Species' traits may provide the necessary insights.

- We conducted a global meta-analysis to determine whether plant leaf and litter functional traits, and particularly leaf and litter nitrogen $(\mathrm{N})$ content and carbon: nitrogen $(\mathrm{C}: \mathrm{N})$ ratio, explain variation in invasive species' impacts on soil $\mathrm{N}$ cycling.

- Dissimilarity in leaf and litter traits among invaded and noninvaded plant communities control the magnitude and direction of invasion impacts on $\mathrm{N}$ cycling. Invasions that caused the greatest increases in soil inorganic $\mathrm{N}$ and mineralization rates had a much greater litter $\mathrm{N}$ content and lower litter $\mathrm{C}: \mathrm{N}$ in the invaded than the reference community. Trait dissimilarities were better predictors than the trait values of invasive species alone.

- Quantifying baseline community tissue traits, in addition to those of the invasive species, is critical to understanding the impacts of invasion on soil $\mathrm{N}$ cycling.

\section{Introduction}

Globalization has increased rates of invasion by exotic species (Sax etal., 2005) and some have dramatic consequences for human and ecosystem health (Ehrenfeld, 2003; Steffen et al., 2015). A critical way through which species invasions alter ecosystems is by increasing soil nitrogen $(\mathrm{N})$ pools and fluxes (Ehrenfeld, 2003; Liao et al., 2008; Vilà et al., 2011; Pyšek et al., 2012), speeding up $\mathrm{N}$ cycling in ways that can be harmful for people and ecosystems by reducing ecosystem nutrient retention, water quality, carbon storage, and increasing greenhouse gas emissions (Ehrenfeld, 2003; Hickman \& Lerdau, 2013). Although these biogeochemical changes can be large (i.e. 50\% faster $\mathrm{N}$ mineralization; Liao et al., 2008), there is significant variability in the direction and magnitude of invasion impacts, and we need a better understanding of factors that mediate the adverse impacts of invasion in order to anticipate and remediate the consequences (Pyšek et al., 2012; Hulme et al., 2013).
Invasive species can impact soil $\mathrm{N}$ cycling through a variety of mechanisms. For example, they can alter the activity or composition of microbial N-transformers (e.g. N-fixing species), and the quality and quantity of plant $\mathrm{N}$ uptake and release (Knops et al., 2002; Hawkes etal., 2005; Chapman etal., 2006). The role of different plant $\mathrm{N}$ uptake and release strategies, as reflected by $\mathrm{N}$-cycling related leaf and litter traits, have not yet been addressed, although previous syntheses have begun to investigate the role of categorical plant traits and climate conditions in mediating the impacts of invasion on soil processes (Liao et al., 2008; Vilà et al., 2011; Castro-Díez et al., 2014). The mediating factor that has received most attention - with good reason - has been whether the invasive species associates with $\mathrm{N}$-fixing bacteria (hereafter, 'N-fixing species'). N-fixing invasive species have larger soil $\mathrm{N}$ effect sizes than non-N-fixing invasive species on average (Liao etal., 2008; Vilà etal., 2011; Castro-Díez etal., 2014). However, even non- $\mathrm{N}$-fixing invasive species are associated with increases in soil $\mathrm{N}$ pools and fluxes (Liao et al., 2008; 
Castro-Díez et al., 2014). Plant species can mediate soil $\mathrm{N}$ pools and fluxes by having either fast nutrient uptake and release, promoting fast $\mathrm{N}$ cycling, or slow nutrient uptake and release, promoting slow N cycling (Knops etal., 2002; Chapman etal., 2006; Laungani \& Knops, 2009; Phillips et al., 2013; Hobbie, 2015). Thus, non-N-fixing species' impacts on soil $\mathrm{N}$ pools and fluxes are likely to be driven by species differences in nutrient uptake and release pathways (Wedin \& Tilman, 1990; Chapman et al., 2006) and, moreover, this may be an underappreciated component of N-fixing species' impacts.

Plant traits, such as leaf $\mathrm{N}$ content and carbon-to-nitrogen $(\mathrm{C}: \mathrm{N})$ ratio, are commonly used to characterize how species process nutrients and thus impact soil N cycling (Suding et al., 2008; Makkonen etal., 2012; Reich, 2014). There is evidence across the globe that invasive species have leaf traits which indicate that they have faster nutrient-use strategies than native species (van Kleunen et al., 2010; Ordonez et al., 2010; but see Funk, 2013). Do these traits drive invasion impacts on $\mathrm{N}$ cycling? Evidence from case studies suggests so, especially for non- $\mathrm{N}$-fixing invasive species (Godoy et al., 2009; González-Muñoz et al., 2013). However, the role of invasive species' leaf and litter traits in driving the direction and magnitude of invasion impacts on soil $\mathrm{N}$ cycling has not been quantified at a global scale.

Traits of the plant community that gets invaded, or the reference community, can have an important influence on the speed, magnitude and/or direction of $\mathrm{N}$ cycling changes following invasion. A previous synthesis supports this hypothesis, finding that invasive $\mathrm{N}$-fixing plants cause stronger impacts on $\mathrm{N}$ pools in communities lacking N-fixers (Castro-Díez et al., 2014). The nutrient content and ratio of the reference community, represented by community-weighted mean (CWM) trait values, are likely to be important because they provide information about $\mathrm{N}$ cycling pool sizes and flux rates in reference area soils (Reich et al., 2001; Cornwell et al., 2008; Craine et al., 2009; Laughlin, 2011; Freschet et al., 2012) and reflect the cumulative effect of plant species on soil N processes (Grime, 1998; Fortunel et al., 2009), weighted by species' relative abundance. These baseline levels of soil $\mathrm{N}$ cycling may be extreme enough that increases or decreases are impossible because of biogeochemical constraints. For example, the increases in $\mathrm{N}$ cycling are less likely for systems with extremely $\mathrm{N}$-rich reference communities because invasive species' traits cannot be more $\mathrm{N}$-rich. However, the roles of reference leaf and litter traits in mediating invasion impacts on soil $\mathrm{N}$ cycling are currently unknown.

Trait dissimilarities between an invaded and reference community have the potential to explain the impact of invasion on $\mathrm{N}$ cycling as a community shifts to being invader-dominated. Invasive species can impact $\mathrm{N}$ cycling via their nutrient-use traits and by displacing native plant species that are likewise important in shaping $\mathrm{N}$ pools and fluxes. Trait dissimilarity addresses both of those impact pathways. In addition, a third mechanism of trait dissimilarity effects is that new combinations of trait values may have synergistic impacts on $\mathrm{N}$ cycling. Whether the addition of litter that is much higher in quality promotes larger or smaller than expected impacts on net $\mathrm{N}$ mineralization due to microbial community mediation, is the subject of continued debate
(Strickland et al., 2009; Pearse et al., 2013). For example, there is evidence that litter mixtures with a diversity of tissue qualities (e.g. high and low litter $\mathrm{N}$ content) undergo decomposition faster than homogenous mixtures due to a complementary suite of resources for decomposing organisms (Gartner \& Cardon, 2004). However, other studies report that decomposition is more rapid for litter mixtures that most closely match the litter quality to which the decomposing organisms are accustomed (e.g. high or low litter N), exhibiting a 'home-field advantage' (Smith \& Bradford, 2003; Strickland et al., 2009; Freschet et al., 2012).

Our objectives in this study are to assess whether the magnitude and direction of $\mathrm{N}$ cycling responses to invasion are a function of (1) invasive species' leaf and litter traits, (2) reference community traits, and (3) trait dissimilarities between invaded and reference communities. To do this, we updated the previous meta-analyses on $\mathrm{N}$ cycling responses to invasion (Liao et al., 2008; Vilà et al., 2011; Castro-Díez et al., 2014) with 67 newly added publications, which constitute $47 \%$ of the full dataset. With this more robust dataset, we test the following hypotheses. We expect that $\mathrm{N}$-fixing invasive species and species with $\mathrm{N}$-rich trait values (e.g. high $\mathrm{N}$ content and low $\mathrm{C}: \mathrm{N}$ ) will have greater impacts (Godoy et al., 2009; González-Muñoz et al., 2013). We expect that reference communities with $\mathrm{N}$-fixing species and $\mathrm{N}$-rich CWM trait values will experience more modest $\mathrm{N}$ cycling shifts (Reich etal., 2001; Cornwell etal., 2008; Craine etal., 2009; Laughlin, 2011; Castro-Díez et al., 2014). We expect that a large degree of trait dissimilarity between invaded and reference communities will explain large impacts (Gartner \& Cardon, 2004; Freschet etal., 2012) and will best predict the direction and magnitude of invasion impacts. Addressing these aims will clarify how, on a global scale, plant invasions impact soil $\mathrm{N}$ cycling, and which factors mediate the direction and magnitude of those impacts.

\section{Materials and Methods}

\section{Study selection}

The aim of the literature search was to collect findings of observational and experimental studies that measure soil nitrogen properties in invaded and reference areas. We evaluated papers cited in Liao et al., 2008 and conducted database searches to collect articles published after 2007 and any articles published before 2007 that might have been overlooked. The search terms for the two Web of Science queries that were conducted on 17 November 2014 were (1) (('invasion' OR 'invasive') AND ('nitrogen cycling' OR 'soil nitrogen') AND ('plant' OR 'grass')) and (2) (('invasion' OR 'invasive') AND ('soil nitrogen' OR 'nitrogen cycling' OR 'soil nutrient')). Related records were also identified if they were cited within any of the full-text articles assessed for eligibility, but were not captured in the literature search. Of the 483 unique articles that were identified, 143 were acceptable for inclusion in this meta-analysis (Supporting Information Fig. S1; Notes S1). Sixty seven of the 143 articles (46.9\%) were unique to this meta-analysis dataset (Table S1). The following criteria were used to identify acceptable articles: (1) article must present data 
on the relationship between an invasive plant species or set of invasive species (up to five species) and soil nitrogen (N) measurements, (2) measurements must be taken in both an invaded and a reference area, (3) must include at least one of the following measurement types: inorganic $\mathrm{N}$ pools, ammonification, nitrification, mineralization or total soil $\mathrm{N}$, and (4) noninvaded reference areas must represent vegetation and soil conditions before or in the absence of invasion.

\section{$\mathrm{N}$ cycling measurements}

As in previous meta-analyses (van Kleunen et al., 2010; Vilà et al., 2011; Castro-Díez et al., 2014; Leffler etal., 2014), we extracted all possible invaded and reference area comparisons reported within each article. We termed each unique comparison a 'study'. Most articles included more than one study, so we accounted for this nested quality of the data structure in our meta-analysis models. Studies within the same article were considered distinct if they presented data from different study types (e.g. field observation and glasshouse study) or sites. Data from repeated measures were aggregated as in Liao et al. (2008). We identified a total of 404 studies.

As available, the following soil measurement data from within invaded and reference plots were collected from each study: soil inorganic $\mathrm{N}$ pool concentrations (ammonium, nitrate, total inorganic $\mathrm{N}$ ), net or gross inorganic $\mathrm{N}$ mineralization rates (ammonification, nitrification, mineralization), soil organic matter, total soil $\mathrm{N}$, and soil carbon-to-nitrogen ratio $(\mathrm{C}: \mathrm{N})$. Measures of inorganic $\mathrm{N}$ represent the balance between supply through mineralization and demand from plant roots and soil microbes.

\section{Leaf and litter traits}

For all invasive species, the following trait data were collected or estimated: leaf $\mathrm{N}$ content, litter $\mathrm{N}$ content, leaf $\mathrm{C}: \mathrm{N}$ and litter $\mathrm{C}: \mathrm{N}$. In cases where there was more than one invasive species in the invaded area, we calculated a weighted average based on species' relative abundances.

We were also interested in trait community-weighted means (CWMs) in invaded and reference communities because invaded areas amount to more than simply the traits of the focal invasive species and, likewise, reference areas often include non-native species. Only a small percentage of studies reported trait CWMs (Table S2). If a CWM trait was not reported, we calculated it by combining study-specific species lists and relative abundances for the appropriate community (invaded or reference) with trait data from the TRY database (Atkin etal., 1997; Niinemets, 1999, 2001; Shipley \& Lechowicz, 2000; White etal., 2000; Ogaya \& Penuelas, 2003; Quested etal., 2003; Wright et al., 2004, 2011; Craine etal., 2005; Han etal., 2005; Louault etal., 2005; Bakker etal., 2006; Kerkhoff etal., 2006; Preston et al., 2006; Kattge et al., 2009, 2011; Freschet etal., 2010; Laughlin et al., 2010; Willis et al., 2010). Some studies provided species lists but did not measure species' relative abundances in invaded and reference areas. In these cases, we extracted relative abundances from authors' in-text descriptions (e.g. 'invader cover was approximately $80 \%$ ') or, lacking any clues, assumed that species were present in equal relative abundance. The assumption was necessary for $19 \%$ (leaf $\mathrm{N}$ content), $22 \%$ (leaf $\mathrm{C}: \mathrm{N}), 45 \%$ (litter $\mathrm{N}$ content) and 21\% (litter C:N) of the CWM trait values on average (Table S3).

Because we needed to estimate many trait CWM values, we assigned each value a quality rank to summarize number of assumptions that entered into the estimate. CWM trait value estimates require knowledge of (1) species' relative abundances in the community and (2) species' mean trait values. Trait data were assigned to species using the highest quality data available from among the following sources (high to low quality): species' mean study-reported trait estimates, species' mean TRY database trait estimates and genus' mean TRY database trait estimates (Table S3). Genus-level data can be a useful approximation of species trait values in their absence (Shan et al., 2012; Schrodt etal., 2015). As such, these estimates are lower in quality if a large proportion of species present in the community (1a) do not have species-specific associated relative abundance data, (1b) do not have any associated relative abundance data, or (2) do not have species-specific trait data. To qualitatively evaluate the significance of CWM data quality in our analyses, we computed a quality rank for each CWM trait value. Values that were reported in the original study are considered highest quality and were assigned a quality rank of four. Values that were estimated were assigned one point if $>25 \%$ of species within the community did not have the low quality characteristics listed above (1a, 1b or 2; Table S3). CWM trait values were only included in our analyses if the observation had at least one invasive and reference species, with each species having a mean trait value for the trait of interest and estimates for the species' abundances in the invaded area and reference area. We were able to obtain leaf $\mathrm{N}$ content trait values and CWMs for the majority of invasive species, and invaded and reference communities (Table S3; Fig. S2), although it was more difficult to assign trait values and CWMs for the other traits: leaf $\mathrm{C}: \mathrm{N}$, litter $\mathrm{N}$ content and litter C: N (Table S3; Fig. S2).

\section{Trait dissimilarities}

Trait dissimilarities were calculated as the univariate difference in CWMs, invaded minus reference, such that higher trait dissimilarity values indicate higher trait values in the invaded than the reference community. Like CWM trait values, CWM trait dissimilarity values were each assigned a quality rank to summarize the number of assumptions that entered into the estimate.

For each CWM trait dissimilarity value, the quality rank was calculated simply as the sum of the CWM trait value quality ranks for the invaded and reference communities (refer to the Leaf and litter traits section) that were used to calculate the trait dissimilarity value, resulting in a maximum quality rank of eight. To determine the importance of calculating trait dissimilarity using the invaded CWM or the invasive species trait value for post hoc analyses, we calculated the dissimilarity between the 
invasive species' trait value and the reference CWM. This resulted in equivalent dissimilarity values for studies where the invaded community was composed of only invasive species $(56 \%$ of this dataset),

\section{Other factors}

We were also interested in the role of $\mathrm{N}$-fixing species' presence in invaded and reference areas (hereafter ' $\mathrm{N}$-fixing status') and study design as factors that mediate the impact of invasive plants on soil $\mathrm{N}$ cycling. Therefore, we categorized studies into an $\mathrm{N}$-fixing status and study type. N-fixing status included four levels: no $\mathrm{N}$-fixers, reference community $\mathrm{N}$-fixers only, invasive species $\mathrm{N}$-fixers only, and reference and invasive species $\mathrm{N}$-fixers (Table S2). Study type included four levels: field observation, field addition, field removal and glasshouse study (Table S2). $\mathrm{N}$-fixing species were identified using the study-specific species lists and a list of Frankia-associated and Actinorhizal plant genera from The Plant List (accessed 11 May 2015, http://www. theplantlist.org/). Regarding study design, a previous metaanalysis found that whether the study was observational, experimental or a combination of both does not change our ability to detect the impacts of invasion on $\mathrm{N}$ cycling. It is important to continue to monitor study design as a potential signal as we add new studies because (1) observational studies are subject to the influence of environmental filtering and are often measuring the effects of long-term invasion, (2) experimental results are contingent on whether invaders are added (Lee et al., 2012) or removed (DeMeester \& deB Richter, 2010), and (3) glasshouse studies are constrained by pot sizes, duration and lack of community effects such as litter accumulation (Lee et al., 2012).

\section{Statistical analyses}

Invasion effect sizes were calculated using Hedges' $d$ effect-size statistics such that reference values were subtracted from invaded area values (Hedges, 1981; Viechtbauer, 2010) (Methods S1). This effect-size metric was chosen instead of the log response ratio used by Liao et al. (2008) because $\mathrm{N}$ mineralization measurements are often measured as net rates and thus can take on negative values. Calculations were done using the ESCALC function with measure $=$ 'SMD' in the METAFOR package of R (Viechtbauer, 2010). Effect sizes greater than zero indicate that measurement values are higher in invaded than reference areas.

We estimated a grand effect size for each soil measurement type in our analyses using linear mixed models, performed with the RMA.MV function and the REML (restricted maximum likelihood) method in the METAFOR package (Methods S2). Each model included nested random effects of study within paper to account for the structure of the dataset (Methods S2). Study effect sizes were evaluated for normality to address model assumptions. In the context of this model, the estimated intercept parameter represents the estimated grand effect size. A test for residual heterogeneity was carried out using the $\chi^{2}$ distribution to determine whether variability in the observed effect sizes or outcomes is larger than one would expect based on sampling variability. Parameter estimates, 95\% confidence intervals, and variance components were also obtained from rma.mv output.

In order to evaluate the role of factors that may mediate the grand effect sizes, we created models to test the significance of the following fixed effects: (a) invasive species' leaf or litter traits, (b) reference CWMs, (c) dissimilarities between invaded and reference CWMs, (d) N-fixing status, and (e) study design (Methods S2). We did not construct models with multiple fixed effects because of the abundance of missing data across studies. We identified models with a significant fixed effect based on a test of residual heterogeneity and accounted for multiple comparisons based on trait type using alpha equal to 0.1 and a sequential Holm-Bonferroni procedure (Holm, 1979). We evaluated the model fit by calculating a pseudo- $R^{2}$ value based on the proportion of variance explained in the full model relative to a reduced model without the fixed effect (Methods S3). For models with a significant fixed effect, we evaluated whether the quality of trait data in that analysis may have biased our findings by regressing trait quality ranks against invasion effect sizes and visually inspecting data by quality rank in the trait-by-effect size scatterplots. For models that included trait dissimilarity as a significant fixed effect, we replaced the trait dissimilarity value with one that was calculated using invasive species' trait values instead of the invaded CWMs and re-ran the model to evaluate whether our findings depend upon noninvasive species that are present in the invaded community. For categorical fixed effects such as Nfixing status and study design, we ran post hoc Wald-type tests to evaluate differences among factor levels.

Meta-analyses can be subject to publication bias (Koricheva et al., 2013). For each effect type, we evaluated publication bias in our dataset by testing for correlation among study effect sizes and sample sizes, looking for asymmetry in funnel plots (Fig. S3), and calculating the failsafe number (Koricheva et al., 2013; Castro-Díez et al., 2014). We did not detect a significant correlation among study effect sizes and sample sizes for any effect types except total inorganic $\mathrm{N}$ effect sizes, which suggests that larger effect sizes in one direction are not more likely to be published for most effect types (Table S4).

All statistical analyses were conducted using $\mathrm{R}$ Statistical Software ( $\mathrm{R}$ Core Team, 2014). The $\mathrm{R}$ packages PLYR and GGPLOT2 were used to visualize data (Wickham, 2009, 2011).

\section{Results}

\section{Global effect sizes}

On average, invaded areas have significantly larger ammonium pools $(+49 \%)$, faster nitrification $(+371 \%)$, faster mineralization rates $(+105 \%)$, more total soil $\mathrm{N}(+65 \%)$ and more soil organic matter $(+37 \%)$ than reference areas (Table 1 , all $P<0.05)$. Total soil inorganic $\mathrm{N}$ tends to be larger in invaded areas $(+94 \%)$ but is not significantly different from zero (Table 1 ). Ammonification rates and soil $\mathrm{C}: \mathrm{N}$ values do not differ significantly in invaded relative to reference areas (Table 1). 
Table 1 Invasion tends to promote larger and faster soil nitrogen $(\mathrm{N})$ pools and fluxes based on four meta-analyses, including this study

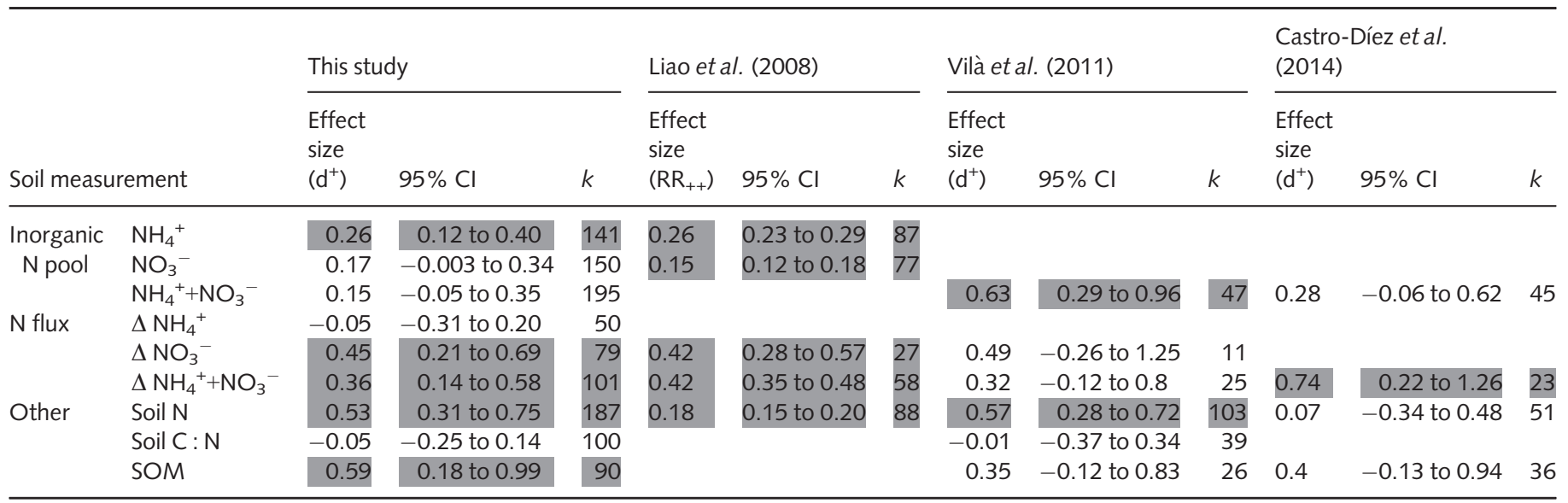

Invasion effect size values for nine measurements that characterize soil inorganic $\mathrm{N}$ pools, fluxes, soil $\mathrm{N}$, carbon (C) : $\mathrm{N}$ and organic matter; mean $\pm 95 \%$ confidence interval with the number of studies, $k$. All effect size values are calculated as Hedges' $d\left(\mathrm{~d}^{+}\right)$, except Liao et al. (2008), which is calculated as a weighted response ratio $\left(R_{++}\right)$. Grey highlight indicates that the $95 \%$ confidence interval does not overlap zero. Effect sizes $>0$ indicate that measurement values are greater in invaded than reference areas.

\section{Invasive species traits}

Of the four types of invasive species traits (leaf $\mathrm{N}$ content, litter $\mathrm{N}$ content, leaf $\mathrm{C}: \mathrm{N}$ and litter $\mathrm{C}: \mathrm{N}$ ) and nine soil $\mathrm{N}$ effect sizes, one trait-by-effect size correlation is significant (Table 2; Fig. S4). Average invasive species' traits are $2.3 \pm 0.1 \%$ leaf N, $1.2 \pm 0.1 \%$ litter $\mathrm{N}, 28.7 \pm 1.0$ leaf $\mathrm{C}: \mathrm{N}$, and $54.2 \pm 4.7$ litter $\mathrm{C}: \mathrm{N}$ (Fig. S2). Invasion increases soil $\mathrm{N}$ to greater extents when the invasive species has high leaf $\mathrm{N}$ content. $\mathrm{CWM}$ value quality was not a significant factor in mediating invasion effect sizes for any of the meta-regression models with a significant fixed effect and visual inspection of scatterplots did not reveal a quality bias (Fig. S4). Moreover, this was the case for all significant models that included CWM trait data (Fig. 1).

\section{Reference CWMs}

Of the four types of reference CWM traits and nine soil $\mathrm{N}$ effect sizes, none of the trait-by-effect size correlations were significant (Table 2). Average reference CWMs were $1.7 \pm 0.0 \%$ leaf $\mathrm{N}$, $1.0 \pm 0.1 \%$ litter $\mathrm{N}, 31.6 \pm 1.2$ leaf $\mathrm{C}: \mathrm{N}$, and $77.9 \pm 5.3$ litter C: N (Fig. S2).

\section{Trait dissimilarities}

Of the four trait dissimilarities among invaded and reference area communities (Inv. - Ref.) and nine soil N effect sizes, four traitby-effect size correlations were significant (Table 2; Fig. 1). Average trait dissimilarities were $+0.38 \pm 0.04 \%$ leaf $\mathrm{N}$ and $+0.19 \pm 0.07 \%$ litter $\mathrm{N}, \quad+0.84 \pm 1.15$ leaf $\mathrm{C}: \mathrm{N}$ and $-17.47 \pm 4.13$ litter $\mathrm{C}: \mathrm{N}$ (Fig. S2). Invasion increased total inorganic $\mathrm{N}$ pools to greater extents when the invaded community had much greater litter $\mathrm{N}$ content and lower litter $\mathrm{C}: \mathrm{N}$ than the reference community (Fig. 1). Invasion increased mineralization rates and decreased soil $\mathrm{C}: \mathrm{N}$ values to greater extents when the invaded community has much lower leaf $\mathrm{C}: \mathrm{N}$ than the reference community (Fig. 1). Similar results were obtained when trait dissimilarity values were recalculated with invasive species' trait values instead of invaded CWM trait values (Table S5).

\section{Presence of $\mathrm{N}$-fixing species}

Most observations did not include an N-fixing species in the reference plant community or as the focal invasive species (295 of 404 studies; Table S2). N-fixing species were present in reference area plant communities in 58 studies and of those studies, 20 studies included an invasive species that is also an $\mathrm{N}$-fixing species (Table S2). A study's N-fixing status was important for explaining three soil $\mathrm{N}$ invasion effect sizes: total inorganic $\mathrm{N}$, soil $\mathrm{N}$ and soil C:N (Fig. 2). For total inorganic N, studies with only resident $\mathrm{N}$-fixers had significantly lower and negative effect sizes than studies without resident $\mathrm{N}$-fixers. In fact, studies with $\mathrm{N}$-fixers only in the reference plant community were the only studies to show a decrease in total inorganic $\mathrm{N}$ in invaded plots. For soil $\mathrm{N}$, studies with only invasive $\mathrm{N}$-fixers tended to have larger soil $\mathrm{N}$ effect sizes, but post hoc tests revealed that the only levels that differed are studies with invasive species $\mathrm{N}$-fixers only and studies without any $\mathrm{N}$-fixers (Fig. 2). For soil C: N, studies with only resident $\mathrm{N}$-fixers had significantly higher soil $\mathrm{C}: \mathrm{N}$ effect sizes than the other $\mathrm{N}$-fixing status levels and higher soil $\mathrm{C}: \mathrm{N}$ values in invaded than reference areas.

\section{Study design}

Observational field studies were by far the most frequent type of study in this dataset (273 of 404 studies; Table S2). Study design was a significant predictor for nitrate and soil organic matter effect sizes (Fig. 3). For nitrate effect sizes, all study designs except observational field studies exhibited neutral or slightly negative effect sizes, whereas observational field studies 


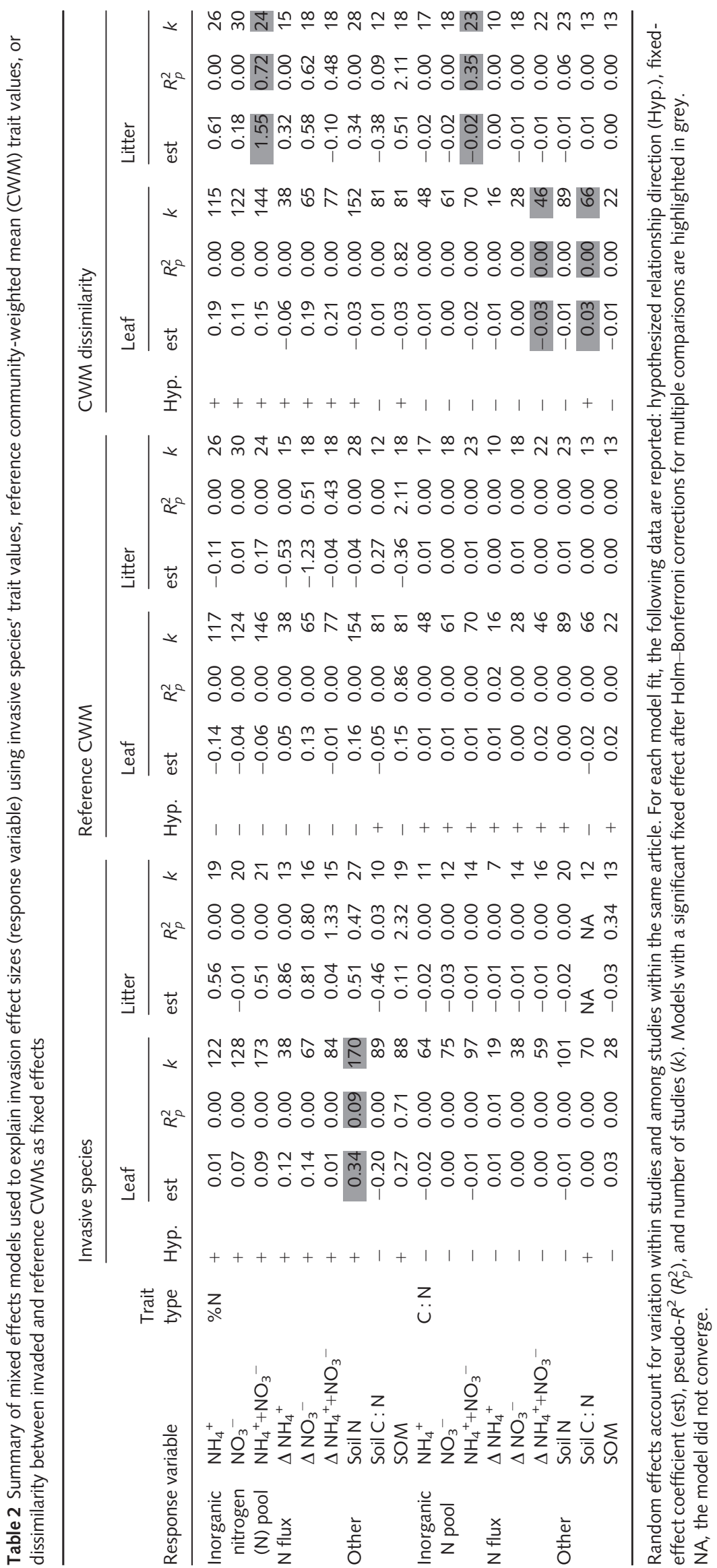


(a)

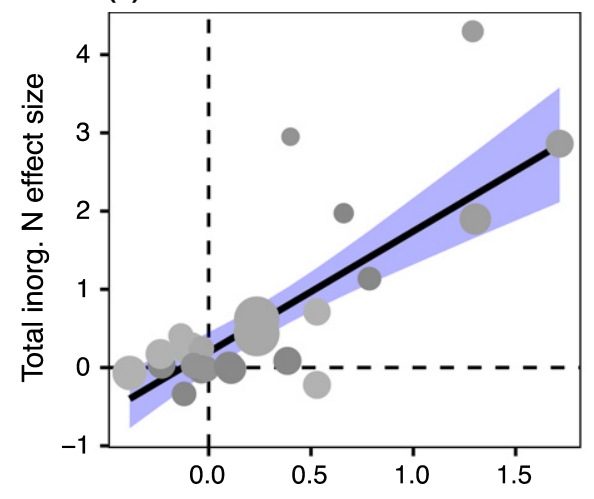

(c) Inv.-Ref. CWM litter $\% \mathrm{~N}$

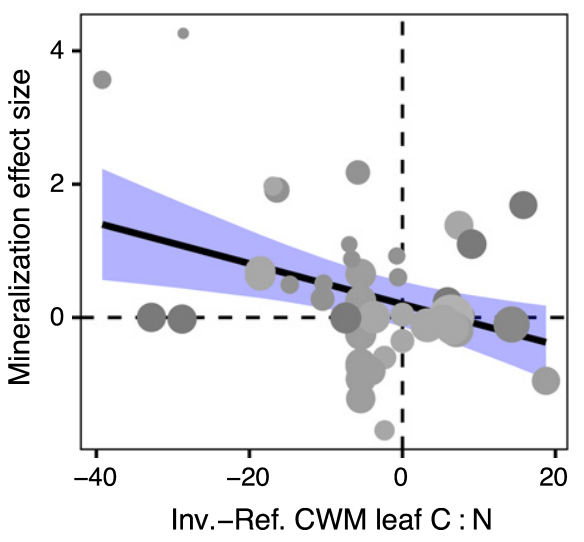

(b)
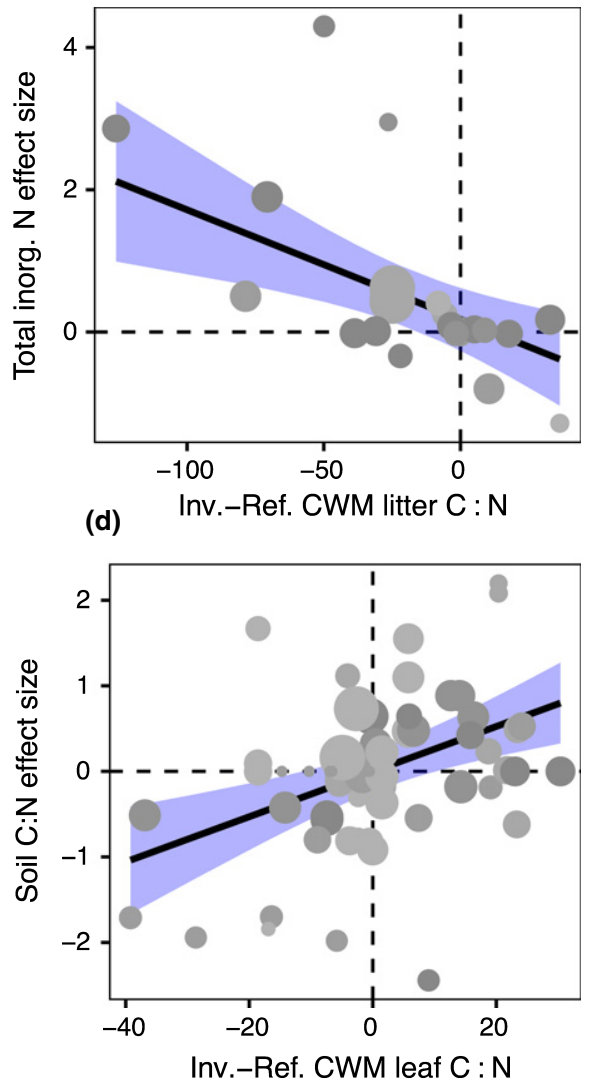

Fig. 1 Community-weighted mean (CWM) trait dissimilarities between invaded and reference plant communities shape the magnitude and direction of invasion impacts on aspects of soil nitrogen ( $\mathrm{N}$ ) cycling. (a) Greater litter $\mathrm{N}$ content and (b) lower litter carbon (C) : $\mathrm{N}$ in invaded (Inv.) than reference (Ref.) communities is associated with larger increases in total inorganic $\mathrm{N}$ due to invasion. Greater leaf $\mathrm{C}: \mathrm{N}$ in invaded than reference communities is associated with (c) smaller increases and even decreases in mineralization and (d) smaller declines and even increases in soil $\mathrm{C}: \mathrm{N}$. Point size is scaled by study variance such that larger points have smaller variance. Point shade represents CWM quality rank such that darker points are higher in quality. Effect sizes greater than zero $(y=0)$ indicate higher soil values in the invaded area. Trait dissimilarities greater than zero $(x=0)$ indicate higher invaded community trait values. Trait dissimilarity is a significant fixed effect in all regression models shown. Solid line and purple shaded region show the meta-regression model fit and the 95\% confidence interval; see Table 2 for fit statistics.

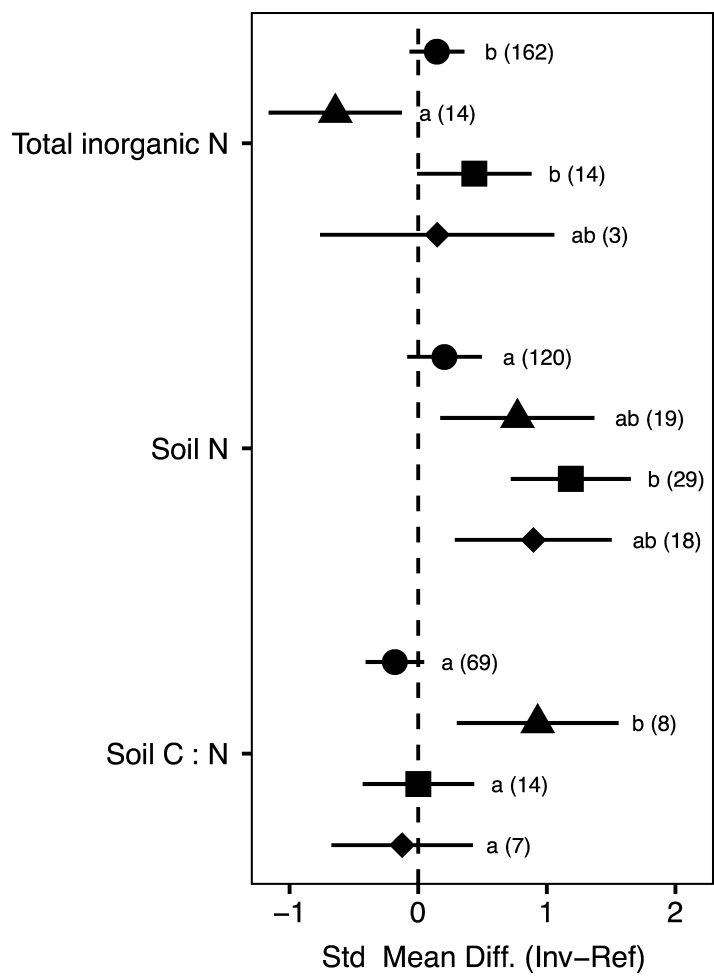

$\mathrm{N}$-fixing status

\section{No $\mathrm{N}$-fixers}

Ref. community $\mathrm{N}$-fixers only

Invasive sp. $\mathrm{N}$-fixers only

Ref. and inv. sp. N-fixers 


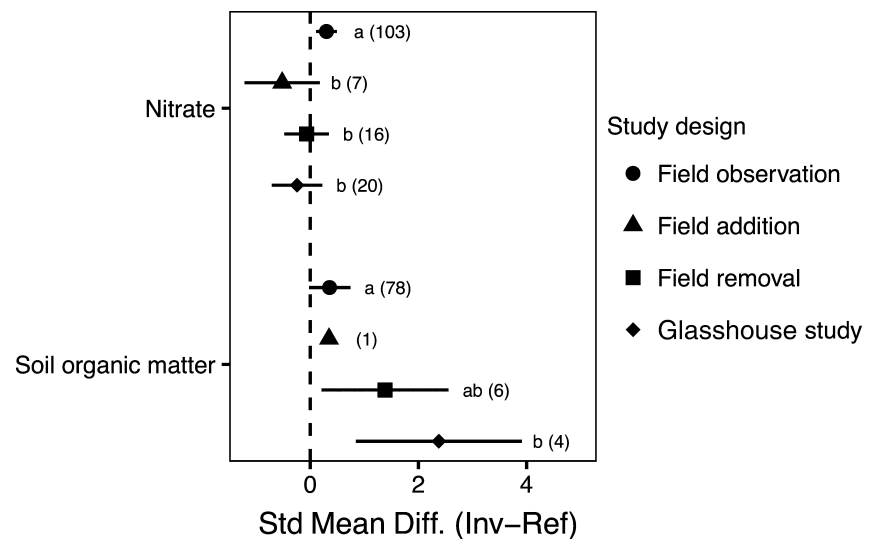

Fig. 3 Study design mediates soil nitrate and organic matter invasion effect sizes. Different letters indicate significant differences among study designs according to post hoc $t$-tests $(\alpha=0.05)$. Effect sizes were calculated as the standard mean difference (Hedges' $d$ ) of invaded minus reference areas such that values $>0$ indicate greater values in invaded than reference areas; mean $\pm 95 \%$ confidence interval with the number of studies shown in parentheses.

found significantly higher nitrate pools in invaded areas relative to reference areas (Fig. 3). Soil organic matter values were marginally to significantly higher in invaded areas for studies that are experimental removals and glasshouse experiment study designs. Soil organic matter effect sizes in observational studies did not significantly differ based on invasion (Fig. 3). Only one experimental addition study measured soil organic matter.

\section{Discussion}

Invasions influence soil nitrogen $(\mathrm{N})$ cycling, fostering ecosystem eutrophication across the globe; however, the extent to which this happens in the presence of invasive species and reference plant communities with $\mathrm{N}$-rich or $\mathrm{N}$-poor litter tissue has been unknown until now. Using a trait-based approach, our meta-analysis provides insight into the importance of leaf and litter traits as drivers of invasive species' impacts on soil $\mathrm{N}$ cycling. Our synthesis shows that the likelihood of an invader enhancing $\mathrm{N}$ cycling depends strongly upon how different that invaders' pattern of nutrient uptake and release is from the community it invades. Invasive species with higher leaf $\mathrm{N}$ content increased soil $\mathrm{N}$ in invaded areas to greater extents. Moreover, dissimilarity in CWM traits among invaded and reference communities performed better than raw CWM trait values at explaining variability in soil $\mathrm{N}$ cycling. Invasions that fostered the greatest increases in total inorganic $\mathrm{N}$ and mineralization rates were those in which the invaded community had much greater litter $\mathrm{N}$ content and lower leaf and litter carbon-to-nitrogen ratio $(\mathrm{C}: \mathrm{N})$ than the reference community. Given these results, future studies should devote more attention to gathering community trait metrics and to quantifying reference or 'baseline' community traits in areas that are vulnerable to invasion.

\section{Global effect sizes}

Invasions are associated with increases in inorganic $\mathrm{N}$ pools, nitrification and mineralization rates, and total soil $\mathrm{N}$ on average. These results fit with previous meta-analyses conducted by Liao et al. (2008), Vilà et al. (2011), and Castro-Díez et al. (2014), and confirm that plant invasions are correlated with a syndrome of $\mathrm{N}$ cycling changes characterized by larger inorganic $\mathrm{N}$ pools and faster $\mathrm{N}$ transformation rates. Our synthesis added 107 new experimental studies with 33 studies that fitted into a new category of study design: experimental addition of invasive species. These studies support the finding that invasions are associated with altered $\mathrm{N}$ cycling, which alleviates some concerns that the 'invasion impact' signal is a cause, rather than a consequence, of invasion. In addition, our synthesis added 189 new studies of non- $\mathrm{N}$-fixing invasive species and, unlike previous syntheses, our dataset included studies where the invasive species is a non$\mathrm{N}$-fixing species and the reference community contains an $\mathrm{N}$-fixing species (16 studies). The fact that adding studies with non-N-fixing invasive species and studies with $\mathrm{N}$-fixing species present in the reference communities are still associated with altered $\mathrm{N}$ cycling, bolsters evidence that invasion causes shifts in $\mathrm{N}$ cycling outside the limited context of $\mathrm{N}$-fixing invasive species that enter communities without an $\mathrm{N}$-fixing species.

\section{Invasive species' leaf and litter traits}

When apparent, the associations that we detected between invader traits and impacts fitted our predictions. Greater invasion impacts were observed when the invasive species had $\mathrm{N}$-rich trait values (e.g. high $\mathrm{N}$ content and low $\mathrm{C}: \mathrm{N}$ ), whereas more modest shifts in $\mathrm{N}$ cycling occurred when the reference community had $\mathrm{N}$-rich CWM trait values. Only one invasive species' plant trait (leaf $\mathrm{N}$ content) explained variation in the magnitude and direction of changes in soil $\mathrm{N}$ due to invasion. In this case, where an invader trait could explain invasion effect sizes on a soil property, our hypotheses regarding the direction of the relationship were supported. The varying explanatory power of different traits for different effect sizes is not surprising given the variation in data coverage among trait types. The trait that was most widely reported in the literature, invasive species' leaf $\mathrm{N}$ content, explained variation in bulk soil properties such as soil $\mathrm{N}$ and soil $\mathrm{C}: \mathrm{N}$. It is impossible to tell whether our inability to detect the effects of other plant traits on $\mathrm{N}$ cycling is a result of the small sample size or an actual lack of effects. Variability in the extent to which these traits are informative could have biological significance, because particular traits may be more or less integral to the ecosystem function of interest (Díaz et al., 2004), and the particular traits that are integral for a species in a given environment may not be the same traits that are integral in the context of a different invasion. For example, Bromus tectorum's leaf N content may be a more important driver of its impact on soil inorganic $\mathrm{N}$ than that of Morella (Myrica) faya, because M. faya's status as an $\mathrm{N}$-fixing species is more closely associated with its soil $\mathrm{N}$ impacts. In addition, some of the ways in which invasive plant species alter soil $\mathrm{N}$ cycling may not have been well characterized by the traits 
included in this study. Belowground plant traits (e.g. mycorrhizal association type or root exudation rate) may have more explanatory power for some invasive species and contexts (Bardgett et al., 2014), but are more rarely measured or reported. Finally, another reason that some traits and effect sizes may not be strongly correlated is because soil $\mathrm{N}$ processes are also regulated by abiotic factors such as soil type, moisture and temperature, which can obscure expected relationships between plant nutrient-use traits and soil $\mathrm{N}$ values (Castro-Díez et al., 2014; Hobbie, 2015).

\section{Reference community leaf and litter traits}

There is limited evidence that reference community characteristics besides $\mathrm{N}$-fixing status shape invasion impacts on $\mathrm{N}$ cycling. As previous studies have found, invasion impacts on $\mathrm{N}$ cycling are diminished where $\mathrm{N}$-fixing species are already present (Vilà et al., 2011; Castro-Díez et al., 2014). However, we did not find that reference CWMs alone were very strong predictors of invader effects on $\mathrm{N}$ cycling. Reference species traits did not contain sufficient information to explain invasion effects on soil $\mathrm{N}$ pools or fluxes. Overall, reference community plant tissue traits did not perform well at explaining variability in invasion impacts, and this might be because reference plant communities can shape $\mathrm{N}$ cycling through many other pathways, such as by altering the abiotic conditions that mediate $\mathrm{N}$ transformations.

\section{Trait dissimilarities}

Dissimilarity in leaf and litter traits among invaded and reference communities explained the magnitude and direction of the most types of invasion impacts on soil $\mathrm{N}$ (i.e. pools, fluxes and bulk soil properties). Trait dissimilarities were able to capture most of the trends detected by invasive species' traits and reference community traits while, in addition, explaining variation in inorganic $\mathrm{N}$ flux effect sizes. This result supports the idea, identified by previous reviewers (Ehrenfeld, 2003; Castro-Díez et al., 2014), that invasive species can have both direct and indirect impacts on $\mathrm{N}$ cycling by having dissimilar characteristics and potentially by displacing native plant species that are likewise important in shaping $\mathrm{N}$ pools and fluxes. To calculate the changes in plant trait values that result from invasion, we used CWM trait estimates from the invaded and reference areas so as to reflect the way that invasion impacts on ecosystem processes are calculated (Garnier etal., 2004; Díaz et al., 2007). Some field studies use CWM traits to explain variation in soil $\mathrm{N}$ cycling in invaded and reference areas, but until now, there has never been a global-scale synthesis to evaluate the explanatory power of this information. Our findings suggest that dissimilarity between how invaded and reference plant communities take up and release nutrients, approximated by leaf and litter traits, is critical to understanding variability in invasion impacts on $\mathrm{N}$ cycling. Whereas leaf $\mathrm{N}$ content was the most informative invasive species' traits, the dissimilarity in $\mathrm{C}: \mathrm{N}$ ratio between invaded and reference communities better explained the impact of invasion on soil $\mathrm{N}$ pools and fluxes. This finding could suggest that plant tissue stoichiometry is a more important indicator of ecosystem sensitivity to soil $\mathrm{N}$ cycling perturbations than plant tissue $\mathrm{N}$ content alone.

\section{Study design}

On the whole, the influence of study design on the magnitude and direction of invasion effect sizes was limited, with only two of nine effect sizes mediated by study design. This fits with the findings of Castro-Díez et al. (2014) in that study design does not appear to strongly mediate detection of invasion impacts on soil $\mathrm{N}$ cycling. But it is important to note that both Castro-Díez et al. (2014) and this study detected a few ways that soil $\mathrm{N}$ cycling measures were sensitive to study design. We found that invasions are associated with larger soil nitrate pools in observational studies but not experimental studies, whereas Castro-Díez etal. (2014) found no difference in invasion effect sizes on soil $\mathrm{N}$ pools and fluxes based on whether the study was observational, experimental or a combination of both. Our finding might suggest that the impact of invasion on nitrate pools develops only after a long lag period because observational studies are more likely to capture an older invasion than manipulative experiments. Another possibility, not mutually exclusive from the previous one, is that high nitrate concentrations promote invasion and are not a consequence of invasion. In contrast to Castro-Díez et al. (2014)'s finding that removal studies have smaller $\mathrm{N}$ pool and flux effect sizes than studies with a noninvaded reference, we found that soil organic matter effect size was the only impact type that was sensitive to experimental removal studies. We found that invaded areas were associated with more soil organic matter in experimental removal and glasshouse studies than observational studies. This finding is supported by just a few studies, but may suggest that experimental removal disrupts soil organic matter whereas glasshouse studies involve extensive root proliferation in invaded pots that is difficult to separate from the soil matrix. Alternatively, we may only be able to detect the impact of invasion on soil organic matter in highly controlled studies such as field and glasshouse experiments. More work is needed to understand why invasion appears to increase soil organic matter in only these study design types. A variety of study designs are needed to understand how invasions influence and are influenced by nitrate and soil organic matter, but on the whole, researchers should be pleasantly surprised to know that observational studies do provide similar insights to invasion impacts as experimental studies.

Further research is needed to address the particular mechanisms that lead to invasion effects on soil $\mathrm{N}$ and how these mechanisms may differ among invasive species and among invaded plant communities. Our findings regarding the relationship (or lack thereof) between plant traits and effect size magnitude and direction point to the need to understand why some plant characteristics are better than others at explaining changes in target ecosystem properties. Last, we recommend considering a measure of functional trait dissimilarity to determine the magnitude and direction that an ecosystem process will shift in response to a change in community composition. Furthering this research will 
contribute to our ability to predict and plan for the impact of plant invasions on nutrient cycling in many contexts.

\section{Acknowledgements}

The study has been supported by the TRY initiative on plant traits (http://www.try-db.org). The TRY initiative and database is hosted, developed and maintained by J. Kattge and G. Bönisch (Max Planck Institute for Biogeochemistry, Jena, Germany). TRY is/has been supported by DIVERSITAS, IGBP, the Global Land Project, the UK Natural Environment Research Council (NERC) through its programme QUEST (Quantifying and Understanding the Earth System), the French Foundation for Biodiversity Research (FRB) and GIS 'Climat, Environnement et Sociéte' France. M.R.L. received funding from the Garden Club of America Wetlands Scholarship, EPA-Science to Achieve Results Graduate Fellowship F13F31249, NSF-Doctoral Dissertation Improvement Grant 1406809, and NSF DEB 1354879. J.P. acknowledges the European Research Council Synergy grant ERC-2013-SyG-610028 IMBALANCE-P. BY benefited from a postdoctoral fund from the French National Research Agency LabEx ANR-10-LABX-0003-BCDiv, in the context of the 'Investissements d'avenir' ANR-11-IDEX-0004-02. We would also like to thank those who helped improve this manuscript: Cari Ficken, Aspen Reese, Bob Shriver and Rachel Mitchell.

\section{Author contributions}

M.R.L., E.S.B. and J.P.W. developed the study idea and analyses; M.R.L. built the meta-analysis dataset and conducted the analyses using data produced by P.M.v.B., J.H.C.C., J.K., D.C.L., U.N., J.P., P.B.R. and B.Y.; M.R.L. wrote the manuscript with assistance from all co-authors.

\section{References}

Atkin OK, Westbeek M, Cambridge ML, Lambers H, Pons TL. 1997. Leaf respiration in light and darkness - a comparison of slow- and fast-growing Poa species. Plant Physiology 113: 961-965.

Bakker C, van Bodegom PM, Nelissen HJM, Ernst WHO, Aerts R. 2006. Plant responses to rising water tables and nutrient management in calcareous dune slacks. Plant Ecology 185: 19-28.

Bardgett RD, Mommer L, de Vries FT. 2014. Going underground: root traits as drivers of ecosystem processes. Trends in Ecology and Evolution 29: 692-699.

Castro-Díez P, Godoy O, Alonso A, Gallardo A, Saldaña A. 2014. What explains variation in the impacts of exotic plant invasions on the nitrogen cycle? A metaanalysis. Ecology Letters 17: 1-12.

Chapman SK, Langley JA, Hart SC, Koch GW. 2006. Plants actively control nitrogen cycling: uncorking the microbial bottleneck. New Phytologist 169: $27-$ 34.

Cornwell WK, Cornelissen JHC, Amatangelo K, Dorrepaal E, Eviner VT, Godoy O, Hobbie SE, Hoorens B, Kurokawa H, Pérez-Harguindeguy N et al. 2008. Plant species traits are the predominant control on litter decomposition rates within biomes worldwide. Ecology Letters 11: 1065-1071.

Craine JM, Lee WG, Bond WJ, Williams RJ, Johnson LC. 2005. Environmental constraints on a global relationship among leaf and root traits of grasses. Ecology 86: $12-19$.

Craine JM, Wright IJ, Reich PB, Elmore AJ, Aidar MPM, Bustamante M, Dawson TE, Hobbie EA, Kahmen A, Mack MC et al. 2009. Global patterns of foliar nitrogen isotopes and their relationships with climate, mycorrhizal fungi, foliar nutrient concentrations, and nitrogen availability. New Phytologist 183: 980-992.

DeMeester JE, Richter D deB. 2010. Differences in wetland nitrogen cycling between the invasive grass Microstegium vimineum and a diverse plant community. Ecological Applications 20: 609-619.

Díaz S, Hodgson JG, Thompson K, Cabido M, Cornelissen JHC, Jalili A, Montserrat-Marti G, Grime JP, Zarrinkamar F, Asri Y et al. 2004. The plant traits that drive ecosystems: evidence from three continents. Journal of Vegetation Science 15: 295-304.

Díaz S, Lavorel S, de Bello F, Quétier F, Grigulis K, Robson TM. 2007. Incorporating plant functional diversity effects in ecosystem service assessments. Proceedings of the National Academy of Sciences, USA 104: 20 684-20 689.

Ehrenfeld JG. 2003. Effects of exotic plant invasions on soil nutrient cycling processes. Ecosystems 6: 503-523.

Fortunel C, Garnier E, Joffre R, Kazakou E, Quested H, Grigulis K, Lavorel S, Ansquer P, Castro H, Cruz P et al. 2009. Leaf traits capture the effects of land use changes and climate on litter decomposability of grasslands across Europe. Ecology 90: 598-611.

Freschet GT, Aerts R, Cornelissen JHC. 2012. Multiple mechanisms for trait effects on litter decomposition: moving beyond home-field advantage with a new hypothesis. Journal of Ecology 100: 619-630.

Freschet GT, Cornelissen JHC, van Logtestijn RSP, Aerts R. 2010. Evidence of the 'plant economics spectrum' in a subarctic flora. Journal of Ecology 98: 362 373.

Funk JL. 2013. The physiology of invasive plants in low-resource environments. Conservation Physiology 1: $\cot 026$.

Garnier E, Cortez J, Billès G, Navas ML, Roumet C. 2004. Plant functional markers capture ecosystem properties during secondary succession. Ecology 85: 2630-2637.

Gartner TB, Cardon ZG. 2004. Decomposition dynamics in mixed-species leaf litter. Oikos 104: 230-246.

Godoy O, Castro-Díez P, van Logtestijn RSP, Cornelissen JHC, Valladares F. 2009. Leaf litter traits of invasive species slow down decomposition compared to Spanish natives: a broad phylogenetic comparison. Oecologia 162: 781-790.

González-Muñoz N, Castro-Díez P, Parker IM. 2013. Differences in nitrogen use strategies between native and exotic tree species: predicting impacts on invaded ecosystems. Plant and Soil 363: 319-329.

Grime JP. 1998. Benefits of plant diversity to ecosystems: immediate, filter and founder effects. Journal of Ecology 86: 902-910.

Han W, Fang J, Guo D, Zhang Y. 2005. Leaf nitrogen and phosphorus stoichiometry across 753 terrestrial plant species in China. New Phytologist 168 377-385.

Hawkes CV, Wren IF, Herman DJ, Firestone MK. 2005. Plant invasion alters nitrogen cycling by modifying the soil nitrifying community. Ecology Letters 8 : 976-985.

Hedges LV. 1981. Distribution theory for Glass's estimator of effect size and related estimators. Journal of Educational and Behavioral Statistics 6: 107-128.

Hickman JE, Lerdau MT. 2013. Biogeochemical impacts of the northward expansion of kudzu under climate change: the importance of ecological context. Ecosphere 4: 1-15.

Hobbie SE. 2015. Plant species effects on nutrient cycling: revisiting litter feedbacks. Trends in Ecology and Evolution 30: 357-363.

Holm S. 1979. A simple sequentially rejective multiple test procedure. Scandinavian Journal of Statistics 6: 65-70.

Hulme PE, Pyšek P, Jarošík V, Pergl J, Schaffner U, Vilà M. 2013. Bias and error in understanding plant invasion impacts. Trends in Ecology and Evolution 28: 212-218.

Kattge J, Díaz S, Lavorel S, Prentice IC, Leadley P, Bönisch G, Garnier E, Westoby M, Reich PB, Wright IJ et al. 2011. TRY - a global database of plant traits. Global Change Biology 17: 2905-2935.

Kattge J, Knorr W, Raddatz T, Wirth C. 2009. Quantifying photosynthetic capacity and its relationship to leaf nitrogen content for global-scale terrestrial biosphere models. Global Change Biology 15: 976-991.

Kerkhoff AJ, Fagan WF, Elser JJ, Enquist BJ. 2006. Phylogenetic and growth form variation in the scaling of nitrogen and phosphorus in the seed plants. American Naturalist 168: E103-E122. 
van Kleunen M, Weber E, Fischer M. 2010. A meta-analysis of trait differences between invasive and non-invasive plant species. Ecology Letters 13: 235-245.

Knops JMH, Bradley KL, Wedin DA. 2002. Mechanisms of plant species impacts on ecosystem nitrogen cycling. Ecology Letters 5: 454-466.

Koricheva J, Gurevitch J, Mengersen K. 2013. Handbook of meta-analysis in ecology and evolution. Princeton, NJ, USA: Princeton University Press.

Laughlin DC. 2011. Nitrification is linked to dominant leaf traits rather than functional diversity. Journal of Ecology 99: 1091-1099.

Laughlin DC, Leppert JJ, Moore MM, Sieg CH. 2010. A multi-trait test of the leaf-height-seed plant strategy scheme with 133 species from a pine forest flora. Functional Ecology 24: 493-501.

Laungani R, Knops JMH. 2009. Species-driven changes in nitrogen cycling can provide a mechanism for plant invasions. Proceedings of the National Academy of Sciences, USA 106: 12400-12405.

Lee MR, Flory SL, Phillips RP. 2012. Positive feedbacks to growth of an invasive grass through alteration of nitrogen cycling. Oecologia 170: 457-465.

Leffler AJ, James JJ, Monaco TA, Sheley RL. 2014. A new perspective on trait differences between native and invasive exotic plants. Ecology 95: 298305.

Liao C, Peng R, Luo Y, Zhou X, Wu X, Fang C, Chen J, Li B. 2008. Altered ecosystem carbon and nitrogen cycles by plant invasion: a meta-analysis. New Phytologist 177: 706-714.

Louault F, Pillar VD, Aufrere J, Garnier E, Soussana JF. 2005. Plant traits and functional types in response to reduced disturbance in a semi-natural grassland. Journal of Vegetation Science 16: 151-160.

Makkonen M, Berg MP, Handa IT, Hättenschwiler S, van Ruijven J, van Bodegom PM, Aerts R. 2012. Highly consistent effects of plant litter identity and functional traits on decomposition across a latitudinal gradient. Ecology Letters 15: 1033-1041.

Niinemets U. 1999. Components of leaf dry mass per area - thickness and density - alter leaf photosynthetic capacity in reverse directions in woody plants. New Phytologist 144: 35-47.

Niinemets U. 2001. Global-scale climatic controls of leaf dry mass per area, density, and thickness in trees and shrubs. Ecology 82: 453-469.

Ogaya R, Penuelas J. 2003. Comparative field study of Quercus ilex and Phillyrea latifolia: photosynthetic response to experimental drought conditions. Environmental and Experimental Botany 50: 137-148.

Ordonez A, Wright IJ, Olff H. 2010. Functional differences between native and alien species: a global-scale comparison. Functional Ecology 24: 1353-1361.

Pearse IS, Cobb RC, Karban R. 2013. The phenology-substrate-match hypothesis explains decomposition rates of evergreen and deciduous oak leaves. Journal of Ecology 102: 28-35.

Phillips RP, Brzostek E, Midgley MG. 2013. The mycorrhizal-associated nutrient economy: a new framework for predicting carbon-nutrient couplings in temperate forests. New Phytologist 199: 41-51.

Preston KA, Cornwell WK, DeNoyer JL. 2006. Wood density and vessel traits as distinct correlates of ecological strategy in 51 California coast range angiosperms. New Phytologist 170: 807-818.

Pyšek P, Jarošík V, Hulme PE, Pergl J, Hejda M, Schaffner U, Vilà M. 2012. A global assessment of invasive plant impacts on resident species, communities and ecosystems: the interaction of impact measures, invading species' traits and environment. Global Change Biology 18: 1725-1737.

Quested HM, Cornelissen JHC, Press MC, Callaghan TV, Aerts R, Trosien F, Riemann P, Gwynn-Jones D, Kondratchuk A, Jonasson SE. 2003. Decomposition of sub-arctic plants with differing nitrogen economies: a functional role for hemiparasites. Ecology 84: 3209-3221.

R Core Team. 2014. R: a language and environment for statistical computing. Vienna, Austria: R Foundation for Statistical Computing.

Reich PB. 2014. The world-wide 'fast-slow' plant economics spectrum: a traits manifesto. Journal of Ecology 102: 275-301.

Reich PB, Peterson DW, Wedin DA, Wrage K. 2001. Fire and vegetation effects on productivity and nitrogen cycling across a forest-grassland continuum. Ecology 82: 1703-1719.

Sax DF, Stachowicz JJ, Gaines SD. 2005. Species invasions. Sunderland, MA, USA: Sinauer Associates.
Schrodt F, Kattge J, Shan H, Fazayeli F, Joswig J, Banerjee A, Reichstein M, Bönisch G, Díaz S, Dickie J et al. 2015. BHPMF - a hierarchical Bayesian approach to gap-filling and trait prediction for macroecology and functional biogeography. Global Ecology and Biogeography 24: 1510-1521.

Shan H, Kattge J, Reich PB, Banerjee A, Schrodt F, Reichstein M. 2012. Gap filling in the plant kingdom - trait prediction using hierarchical probabilistic matrix factorization. In: Langford J, ed. Proceedings of the International Conference for Machine Learning (ICML). Edinburgh, UK: International Conference on Machine Learning. 1303-1310.

Shipley B, Lechowicz MJ. 2000. The functional co-ordination of leaf morphology, nitrogen concentration, and gas exchange in 40 wetland species. Ecoscience 7: 183-194.

Smith VC, Bradford MA. 2003. Do non-additive effects on decomposition in litter-mix experiments result from differences in resource quality between litters? Oikos 102: 235-242.

Steffen W, Richardson K, Rockström J, Cornell SE, Fetzer I, Bennett EM, Biggs R, Carpenter SR, de Vries W, de Wit CA et al. 2015. Sustainability. Planetary boundaries: guiding human development on a changing planet. Science 347: 1259855 .

Strickland MS, Lauber CL, Osburn E, Fierer N, Bradford MA. 2009. Litter quality is in the eye of the beholder: initial decomposition rates as a function of inoculum characteristics. Functional Ecology 23: 627-636.

Suding KN, Lavorel S, Chapin FS. 2008. Scaling environmental change through the community-level: a trait-based response-and-effect framework for plants. Global Change Biology 14: 1125-1140.

Viechtbauer W. 2010. Conducting meta-analyses in $\mathrm{R}$ with the metafor package. Journal of Statistical Software 36: 1-48.

Vilà M, Espinar JL, Hejda M, Hulme PE, Jarošík V, Maron JL, Pergl J, Schaffner U, Sun Y, Pyšek P. 2011. Ecological impacts of invasive alien plants: a meta-analysis of their effects on species, communities and ecosystems. Ecology Letters 14: 702-708.

Wedin DA, Tilman D. 1990. Species effects on nitrogen cycling - a test with perennial grasses. Oecologia 84: 433-441.

White MA, Thornton PE, Running SW. 2000. Parameterization and sensitivity analysis of the BIOME-BGC terrestrial ecosystem model: net primary production controls. Earth Interactions 4: 1-85.

Wickham H. 2009. ggplot2: elegant graphics for data analysis. New York, USA: Springer-Verlag.

Wickham H. 2011. The split-apply-combine strategy for data analysis. Journal of Statistical Software 40: 1-29.

Willis CG, Halina M, Lehman C, Reich PB, Keen A, McCarthy S, CavenderBares J. 2010. Phylogenetic community structure in Minnesota oak savanna is influenced by spatial extent and environmental variation. Ecography 33: 567-577.

Wright IJ, Reich PB, Westoby M, Ackerly DD, Baruch Z, Bongers F, Cavender-Bares J, Chapin FS, Cornelissen JHC, Diemer M et al. 2004. The worldwide leaf economics spectrum. Nature 428: 821-827.

Wright SJ, Yavitt JB, Wurzburger N, Turner BL, Tanner EVJ, Sayer EJ, Santiago LS, Kaspari M, Hedin LO, Harms KE et al. 2011. Potassium, phosphorus, or nitrogen limit root allocation, tree growth, or litter production in a lowland tropical forest. Ecology 92: 1616-1625.

\section{Supporting Information}

Additional Supporting Information may be found online in the Supporting Information tab for this article:

Fig. S1 Flow chart of the article identification and selection process.

Fig. S2 Frequency distribution of invasive species' trait values and CWM trait dissimilarities.

Fig. S3 Effect-size funnel plots. 
Fig. S4 Invasive species' with higher leaf $\% \mathrm{~N}$ promote greater increases in soil $\mathrm{N}$.

Table S1 List of the 143 articles used in our meta-analysis on the impacts of invasion on soil $\mathrm{N}$ cycling and the type of data extracted

Table S2 Predictor variables used to explain variation in invasion impacts on soil $\mathrm{N}$ cycling in this study

Table S3 Summary of trait data quality by community and trait type

Table S4 Impact of invasion on soil $\mathrm{N}$ cycling with associated publication bias checks and $\mathrm{Q}$ statistics

Table S5 Mixed effects model results that included trait dissimilarity as a significant fixed effect (Invaded - Reference CWM) and the results of re-running that model with trait dissimilarity calculated as the invasive species trait value minus the reference CWM (Invasive sp. - Reference CWM)

Methods S1 Hedges' d calculation.

Methods S2 R code for meta-analysis and meta-regression models.

Methods S3 Pseudo- $R^{2}$ calculation.

Notes S1 Invasion impacts on soil nitrogen cycling references.

Please note: Wiley Blackwell are not responsible for the content or functionality of any Supporting Information supplied by the authors. Any queries (other than missing material) should be directed to the New Phytologist Central Office.

\section{About New Phytologist}

- New Phytologist is an electronic (online-only) journal owned by the New Phytologist Trust, a not-for-profit organization dedicated to the promotion of plant science, facilitating projects from symposia to free access for our Tansley reviews.

- Regular papers, Letters, Research reviews, Rapid reports and both Modelling/Theory and Methods papers are encouraged. We are committed to rapid processing, from online submission through to publication 'as ready' via Early View - our average time to decision is $<28$ days. There are no page or colour charges and a PDF version will be provided for each article.

- The journal is available online at Wiley Online Library. Visit www.newphytologist.com to search the articles and register for table of contents email alerts.

- If you have any questions, do get in touch with Central Office (np-centraloffice@lancaster.ac.uk) or, if it is more convenient, our USA Office (np-usaoffice@lancaster.ac.uk)

- For submission instructions, subscription and all the latest information visit www.newphytologist.com 